\section{Diagnosis and treatment of Parkinson's disease}

\section{Anosmia is a common finding}

EDITOR,-Niall Quinn's review on the recognition and differential diagnosis of parkinsonism ${ }^{1}$ omits an important point-namely, that at least $70 \%$ of patients with idiopathic Parkinson's disease have a defective or absent sense of smell. ${ }^{23}$ About $90 \%$ of patients have rigidity and akinesia, and hence impairment of the sense of smell would be the second commonest feature of this condition, at least equalling tremor in its frequency of occurrence. About half of patients are aware of this defect, and it is suspected, although not yet proved, that anosmia may precede the onset of the motor aspects of idiopathic Parkinson's disease.

This observation has important clinical consequences. If one suspects a patient to have idiopathic Parkinson's disease and the result of a simple bedside test of olfaction is normal then the diagnosis should be questioned. In progressive supranuclear palsy (Steele-Richardson syndrome), which may simulate idiopathic Parkinson's disease, olfaction is normal. ${ }^{4}$ Furthermore, provisional information suggests that patients with benign essential tremor also have normal smell identification scores. ${ }^{3}$ This might not permit the distinction from benign tremulous Parkinson's disease as ou limited data suggest that olfaction is normal in this rare variety of parkinsonism.

An ideal test for olfactory identification is the University of Pennsylvania smell identification test. Unfortunately, this is quite expensive, but preliminary assessment may be made with everyday odours such as chocolate, orange peel, coffee, rose, and vanilla. As long as local nasal disease is excluded an important clinical sign may be documented.

C M HAWKES

Department of Clinical Neurology, Ipswich Hospital,
Ipswich IP4 5PD

1 Quinn N. Parkinsonism-recognition and differential diagnosis. $B M 7$ 1995;310:447-52. (18 February.)

2 Doty RL, Deems DA, Stellar S. Olfactory dysfunction in parkinsonism: a general deficit unrelated to neurologic signs, disease stage or disease duration. Neurology 1988;38:1237-44.

3 Hawkes CH, Shephard BC. Olfactory impairment in Parkinson's disease: evidence of dysfunction measured by olfactory evoke potentials and smell identification tests. Ann Neurol 1992;32: 248.

4 Wenning GK, Shephard B, Hawkes CH, Lees A, Quinn N Olfactory function in progressive supranuclear palsy and corticobasal degeneration. I Neurol Neurosurg Psychiatry 1994; 57:251-2.

5 Busenbark KI, Huber SJ, Greer G, Pahwa R, Koller WC Olfactory function in essential tremor. Neurology 1992;42: 1631-2.

\section{Anticholinergic drugs are not contraindicated after iridotomy}

EdTOR,-In his review of the drug treatment of Parkinson's disease Niall Quinn states mistakenly that anticholinergic drugs are contraindicated in narrow angle glaucoma. ${ }^{1}$ Similar misleading advice continues to be published in various pharmacopoeias (for example, the British National Formulary) with reference to other drugs with anticholinergic effects, including antidepressants and bladder relaxants. In addition, general practitioners commonly cite a history of glaucoma

\section{Advice to atithor}

We prefer short letters that relate to recently published article and we are unlikely to publish letters longer than 400 words and containing over five references. Letters may be shortened. Your letters should be typed with double spacing and include a word count. All authors need to sign the letter and provide one current appointment and address. We encourage you to declare any conflict of interest. Please enclose a stamped addressed envelope if you require an acknowledgment.

as a reason for not dilating patients' eyes when screening for diabetic retinopathy. ${ }^{2}$

When acute narrow angle glaucoma is confirmed laser iridotomy should be performed to prevent any recurrence; this renders pupil dilatation safe. Chronic open angle glaucoma, by definition, does not predispose to angle closure. When doubt persists the eye department should be consulted.

Acute narrow angle glaucoma is rare and confined almost exclusively to people with severe hypermetropia and elderly people. Good practice dictates that patients should always be warned about potential side effects of newly prescribed drugs so that help can be requested at an early stage and permanent harm prevented. Current advice to doctors on the use of anticholinergic drugs, however, seems to be in need of review. Many patients with relatively common conditions are at risk of being deprived of their most suitable drug treatment because of exaggerated and erroneous fears of precipitating a relatively uncommon condition.

ANDREW FINK

Chaim Sheba Medical Centre,

Maurice and Gabriela Goldschleger Eye Institute,

Tel-Hoshomer, Israel

1 Quinn N. Drug treatment of Parkinson's disease. BMf 1995; 310:575-9. (4 March.)

Fink A, Wright L, Wormald R. Detection and prevention of treatable visual failure in general practice: room for improvement? Br $\mathcal{F}$ Gen Pract 1994;44:587-9.

\section{Author's reply}

EDrToR,-I agree with $\mathrm{C} \mathrm{H}$ Hawkes that the question of impaired olfaction is of interest in the differential diagnosis of parkinsonism. Although I did not address this in my review because of limitations on space, colleagues (including Hawkes) and I have shown that a score of 25/40 in the University of Pennsylvania smell identification test gives a sensitivity of $77 \%$ and a specificity of $85 \%$ in differentiating idiopathic Parkinson's disease from progressive supranuclear palsy, corticobasal degeneration, and multiple system atrophy. ${ }^{1}$ On a group basis, olfaction in the first two of these conditions did not differ significantly from that in normal controls, but olfaction in the group with multiple system atrophy, while significantly better than that in the group with idiopathic Parkinson's disease, was also significantly worse than that in the control group. Scores below the lower limit of the $95 \%$ confidence interval for controls were found in $51 \%$ of patients with idiopathic Parkinson's disease, $31 \%$ of those with multiple system atrophy, $20 \%$ of those with progressive supranuclear palsy, and none of seven with corticobasal degeneration. Interpretation of the diagnostic importance of olfactory impairment in individual cases rather than between groups must therefore be made with caution.

Andrew Fink takes me to task for stating that anticholinergic drugs are contraindicated in narrow angle glaucoma. He is correct in stating that if this has already been treated by iridotomy then these drugs are not contraindicated. Anticholinergic drugs can, however, cause blindness in patients who have not been treated by iridotomy by precipitating narrow angle glaucoma. Indeed, three such cases caused by benzhexol were reported in the $B M F$ in 1972 by Israeli ophthalmologists.

NIALL QUINN

Institute of Neurology,

Reader in clinical neurolog

London WC1N $3 B$

1 Wenning GK, Shephard B, Hawkes C, Petruckevitch A Lees A, Quinn N. Olfactory function in typical parkinsonia syndromes. Acta Neurol Scand 1995;91:247-50.

2 Friedman Z, Neumann E. Benzhexol-induced blindness in Parkinson's disease. BMF 1972;i:605.

\section{Alcoholism and rising mortality in the Russian Federation}

EdrToR,-Michael Ryan's article ${ }^{1}$ and the press coverage that followed it highlight how little is known in the West about the human tragedy currently unfolding in Russia. Although the nonIslamic republics of the former Soviet Union have a long tradition of high alcohol consumption, until recently epidemiological research on it was suppressed as this was the reponsibility of the Ministry of Internal Affairs. ${ }^{2}$ This latter factor may explain the remarkable absence of references to alcohol in major Western reports on health in the former Soviet Union.

Ryan notes that if the change in life expectancy coinciding with Gorbachev's antialcohol campaign had been seen in a Western country it would seem improbable and some might be inclined to dismiss it as propaganda. We have also experienced disbelief in the magnitude of this effect, but considerable evidence supports it. This includes the observation that similar changes took place in all the European republics of the former Soviet Union (figure). Each experienced a dramatic increase between 1985 and 1986, typically of the order of two years. Since then the direction of change has reversed dramatically in all republics. Studies in the Russian literature of experience at local level also report quite large reductions in rates of admission to hospital and death rates (in both cases over $30 \%$ ), due in large part to a reduction in violence related to alcohol. ${ }^{3}$

There can now be little doubt that the campaign in 1985, described in detail by Tarschys, ${ }^{2}$ was extraordinarily effective. It involved a range of approaches, including reducing access through the closure of outlets and restricting sales to after $2 \mathrm{pm}$, increasing prices, police action, media campaigns, and the creation of antialcohol movements. Detailed analysis of consumption patterns, with allowance being made for illicit production, shows a considerable, if short lived, fall in consumption. ${ }^{4}$ This is all the more amazing given the strong 